\title{
Pathways to Digital Service Innovation: The Role of Digital Transformation Strategies in Established Organizations
}

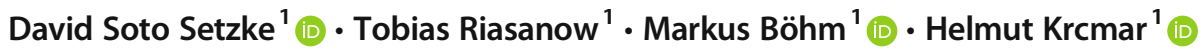

Accepted: 25 January 2021

(C) The Author(s) 2021

\begin{abstract}
Digital technologies are radically changing how established organizations design novel services. Digital transformation (DT) strategies are executed to manage the transition from product-centric to service-centric business models based on digital technologies. However, little is known about what configurations of DT strategies lead to successful digital service innovation (DSI) in established organizations. We employ fuzzy-set Qualitative Comparative Analysis on a set of 17 case studies of DT strategies from established organizations with different industry backgrounds. We identify several distinct configurations of DT strategies that lead to successful and unsuccessful DSI. Based on these configurations, we deduce that the threat of digital disruption negatively impacts an organization's innovation activities. Furthermore, we find that strategic partnerships can be leveraged by organizations that face an imminent threat of digital disruption while organizations with competitive advantages may rely on "doit-yourself" approaches. Lastly, we find that the involvement of a C-level executive is a necessary requirement for successful DSI. Our results contribute to theory by integrating research on DSI and DT, providing a perspective on DSI failure, and employing a configurational research approach that allows us to highlight interdependencies between factors as well as insights into the individual factors. Furthermore, we provide actionable recommendations for executives.
\end{abstract}

Keywords Digital transformation · Digital service innovation · Radical service innovation · Digital transformation strategies · Qualitative comparative analysis

\section{Introduction}

Service innovation plays a decisive role in our society. The continuous refinement and development of radically new services have brought substantial advances to the individuum, companies, and society as a whole (Miles 2005). The widespread availability of digital technologies such as in-memory databases, cloud computing, or distributed ledgers enables organizations to radically transform value propositions.

David Soto Setzke

david.soto.setzke@tum.de

Tobias Riasanow

tobias.riasanow@tum.de

Markus Böhm

markus.boehm@tum.de

Helmut Krcmar

helmut.krcmar@tum.de

1 Chair of Information Systems, Technical University of Munich, Boltzmannstr. 3, 85748 Garching bei München, Germany
These advancements enable higher accuracy and efficiency to meet economic needs, and also tackle worldwide challenges and pave the way for sustainable societies (Pappas et al. 2018). This comprises a multitude of sectors and use cases: for example, platform-based service concepts such as crowdsourced delivery have the potential to significantly reduce traffic and pollution in densely populated areas (Paloheimo et al. 2016). In developing economies and rural areas, financial services offered by so-called mobile money operators enable financial access and inclusion for disadvantaged communities (Economides and Jeziorski 2017). In the health care sector, novel devices such as wearables or smart glasses improve the quality of treatments and patient care (Klinker et al. 2020). To effectively design and develop these new services, established organizations need to embrace digital technologies and integrate them into their processes, organizational structures, and working models, a process known as digital transformation (DT) (Vial 2019). While information systems (IS) research and organization/management theory (OMT) have a long history of exploring the relationship between technology and organizational change, the phenomenon of DT is novel concerning the use of digital technologies 
(Besson and Rowe 2012). They differ from earlier technologies in their inherent characteristics such as programmability, the homogenization of data, and their self-referential nature (Yoo et al. 2010). Thus, the transformational abilities of digital technologies go further than merely automating processes and satisfying information needs to enable fundamental changes in a company's business model (Besson and Rowe 2012). This also implies that DT is not merely "old wine in new bottles" and learnings from earlier schools of thought may not necessarily apply to the logic of DT (Vial 2019).

Extant research on service innovation acknowledges the importance and game-changing nature of DT (Goduscheit and Faullant 2018; Barrett et al. 2015; Lusch and Nambisan 2015). So far, research on DSI and DT has highlighted process models for agile co-creation (Sjödin et al. 2020), organizational enablers in established companies with data-rich environments (Troilo et al. 2017), and design frameworks for service innovation in the context of smart product-service systems (Zheng et al. 2018). Furthermore, there are articles about the importance of digital service innovation (DSI) for including service-disadvantaged communities (Srivastava and Shainesh 2015), archetypes of service innovations in the sharing economy (Frey et al. 2019), and scaling contact-intensive services through the use of IT (Kleinschmidt et al. 2019). Various scholars have explored the formation and execution of DT strategies as well as the emergence of new executive roles, such as the Chief Digital Officer (CDO), and their integration into the organization (Chanias et al. 2019; Hanelt et al. 2020; Singh et al. 2019).

However, little is known about how the building blocks of DT strategies impact service innovation. IS research has explored the characteristics of DT strategies and their impact on innovation processes mostly through conceptual works and single or multiple-case studies (Matt et al. 2015; Hess et al. 2016; Chanias et al. 2019). We argue that these case studies are highly context-dependent, with limited generalizability. Companies such as SAP or Siemens have successfully managed to transition from a product-centric to a service-centric business model using digital technologies. Both companies designed and executed large-scale DT strategies to manage this transition. However, the mere existence and formulation of a strategy do not guarantee its success. Although General Electric (GE) equipped many of its products with sensors, built its own Internet of Things platform, and developed new digitally-enabled services, its stock price continued to languish which eventually led to the departure of its former CEO. This suggests that the success of DSI depends on different factors, which may not be uncovered through a singlecase study alone. As can be observed in the mentioned case of GE, a strategy that may have worked effectively for one organization may not easily be transferable to another. Research on DT strategies, however, has so far mainly investigated how DT strategies are formulated and executed, but not their degree of success (Berghaus and Back 2017; Matt et al. 2015). Against this background, we argue that combining DT strategies and service innovation enables the filling of a theoretical research gap as well as providing actionable guidelines for practitioners. Thus, we investigate the building blocks of a DT strategy that lead to successful DSI. Since these elements may depend on each other and contextual or environmental factors, we employ configuration theory. As a result, the research question that guides this paper is as follows:

RQ: What configurations of digital transformation strategies lead to successful and unsuccessful digital service innovation?

To address this question, we first carried out exploratory, in-depth case studies with 17 established organizations that have recently formulated and launched a DT strategy. To systematically compare these cases and to derive configurations, we chose the set-theoretic method of fuzzy-set Qualitative Comparative Analysis (fsQCA) (Ragin 2008). Our analysis yields two configurations for successful and three configurations for unsuccessful DSI. Our study makes several contributions. First, we integrate the literature on DSI and DT strategies to paint a more complete picture of these complex and interrelated phenomena. Second, we add a perspective on DSI failure to the predominant focus on DSI success. Third, we employ a configurational viewpoint to investigate our research question, following recent calls for both DT research (Riasanow et al. 2019; El Sawy et al. 2010) and service (innovation) research (Goduscheit and Faullant 2018; Kohtamäki et al. 2019). This enables us to highlight the interdependencies between the different DT strategy building blocks and shed light on the individual factors and explore their contributions to DSI at the same time. Fourth, we provide actionable insights for practitioners regarding the design of DT strategies.

\section{Conceptual Background}

\subsection{Digital Service Innovation}

The concept of service innovation emerged recently and as a result, it is still far from having an established common understanding among scholars (Goduscheit and Faullant 2018). Service-dominant (S-D) logic is a frequently used conceptual framework that interprets service innovation as "the creation of new value propositions by means of developing existing or creating new practices and/or resources, or by means of integrating practices and resources in new ways" (Skålén et al. 2014). Concerning its degree of change, service innovation can be categorized as either incremental or radical 
(Goduscheit and Faullant 2018). While incremental innovation is associated with only minor changes to the already existing characteristics of a service's value proposition, radical innovation refers to an entirely new set of characteristics (Johansson et al. 2019). For example, a tracking system for door-to-door deliveries adds value through the use of digital technologies to an already existing service and can, therefore, be classified as incremental service innovation (Cheng 2011). On the other hand, providers such as Amazon are implementing radical innovations through the use of internet technologies by changing how the benefits of their services are delivered (Cheng 2011). In highly competitive environments, pursuing radical service innovation has been identified as a critical success factor for achieving high performance and service quality (Sok and O'Cass 2015). Recently, the widespread availability of different digital technologies has led to a multitude of startups disrupting traditional markets and, therefore, increasing competition. Thus, established organizations are challenged to engage in radical service innovation that builds on the distinctive features of digital technologies (Lusch and Nambisan 2015; Yoo et al. 2012; Sklyar et al. 2019).

Several scholars have highlighted the role of digital technologies in service innovation (Lusch and Nambisan 2015; den Hertog 2000; Goduscheit and Faullant 2018). Extant research has also demonstrated that technology is a fundamental enabler of service innovation (Troilo et al. 2017), and, in particular, a major driver for achieving radical service innovation in established organizations (Goduscheit and Faullant 2018). A major focus of extant research is the process of DSI. The challenge of managing efficient value co-creation can be tackled by using an agile micro-service innovation approach (Sjödin et al. 2020). To ensure successful cooperation and governance, relational teams that integrate knowledge from both providers and customers are required. To connect datarich organizational environments with opportunities for service innovation, data density processes need to be implemented (Troilo et al. 2017). To make these processes more effective, companies are required to design a customer-centric, data-oriented organizational culture, and to implement strong support from senior management (Troilo et al. 2017). Various articles have also investigated the characteristics and benefits of DSI. In particular, it can be used to include servicedisadvantaged communities, for example, in the context of healthcare or finance (Srivastava and Shainesh 2015; Economides and Jeziorski 2017). Depending on the specific context, there are also distinct archetypes of innovation (Frey et al. 2019). While DSI provides various benefits for organizations, it also comes with serious challenges since it "requires a change in managing provider-customer relationships by adopting new and innovative co-creation approaches" (Sjödin et al. 2020, p. 479). While extant literature provides multiple insights into organizational enablers and process frameworks for DSI (Goduscheit and Faullant 2018; Troilo et al. 2017; Sjödin et al. 2020), so far it has not shed light on the role of DT strategies in achieving radical innovations.

\subsection{Digital Transformation Strategies}

DT is "a process that aims to improve an entity by triggering significant changes to its properties through combinations of information, computing, communication, and connectivity technologies" (Vial 2019, p. 118). For the remainder of this paper, we use organizations as the entity of interest. Significant change refers, among other things, to the "creation of new value propositions that rely increasingly on the provision of services" (Vial 2019, p. 125). To trigger or to enable DSI, established organizations (so-called brick-and-mortar firms) design large-scale DT strategies (Matt et al. 2015; Hess et al. 2016). This type of strategy has appeared relatively recently and complements an organization's existing repertoire of IT and digital business strategies. While these strategies focus on managing a firm's internal IT infrastructure with little to no impact on innovation or potential future business opportunities based on digital technologies, DT strategies focus on the transformational steps needed to realize future opportunities (Matt et al. 2015). In this paper, we suggest DT as an appropriate antecedent for DSI in established organizations. In particular, we focus on DT strategies that aim to induce the process of DT at an organizational level (Matt et al. 2015). Research on DT strategies is still in its infancy, due to its relatively recent emergence and focuses mainly on the formation and execution of strategies (Vial 2019; Hanelt et al. 2020). DT strategies are often initially shaped by separate sub-communities in an organization (Chanias and Hess 2016). Management then tries to align these efforts to the already existing strategy, leading to a highly dynamic process that iterates between learning and doing (Chanias and Hess 2016; Chanias et al. 2019). In the initial stage of the transformation, companies may choose a centralized or a decentralized approach for implementing the strategy (Berghaus and Back 2017; Singh et al. 2019). This often involves a Chief Digital Officer (CDO) who leads and initiates the transformational endeavor (Haffke et al. 2016). Depending on the organization's strategic focus, the specific tasks of the $\mathrm{CDO}$ and their anchoring in the organization may vary. For example, CDOs that fulfill the role of change agents may predominantly rely on formal coordination mechanisms, such as cross-functional steering committees (Singh et al. 2019). Innovation-focused CDOs, on the other hand, may focus more on informal coordination mechanisms, such as brainstorming or ideation sessions (Singh et al. 2019). When designing DT strategies, organizations often have a wide range of options to choose from (Hess et al. 2016). These include questions of leadership (who is in control of DT), organizational structures (how should organizational structures adapt), and outsourcing 
(what needs to be done by the organization itself and what can be done by partners/service providers).

The transformative nature of digital technologies poses the question of how to adapt organizational structures, i.e. the concept of structural separation. Several scholars posit that existing organizational structures are often not an adequate environment to explore digital innovation and exploit its business potential (Teece 1996; Yoo et al. 2012). What changes should be made and how is heavily debated in different literature streams (Dixon et al. 2017; Haffke et al. 2016; Markides 2013). Separating different parts of the organization not only from an organizational structure point of view but also physically likely favors innovation-related activities (de Visser et al. 2010). On the other hand, organizations may choose to fully incorporate new activities into existing corporate structures either without or with only minor organizational changes, resulting in lower restructuring efforts. Close integration with the core business can lead to increased collaboration between business units and thus favor synergies between old and new parts of an organization. Matt et al. (2015) suggest that for smaller changes in products or processes, integration into existing corporate structures may be favorable. For substantial changes, however, separate subsidiaries such as new business units or spin-offs should be chosen. New organizational units are often implemented as so-called digital innovation labs (DILs). These are separate units, intended to bundle an organization's innovation activities and capabilities (Hund et al. 2019). Spin-offs, however, are entirely separated from the main organization's corporate structure and are often completely autonomous entities. This may increase decisionmaking speed as well as response times to market changes. As an additional benefit, separation also prevents spillovers of corporate culture, policies, and systems that hinder innovation activities (Sklyar et al. 2019). Still, spin-offs pose new challenges to the main organization. Embedding them may result in difficulties, especially when trying to integrate them again in the future (Dixon et al. 2017). Furthermore, separating innovation activities from the main organization may also lead to failure in synergy exploitation and a risk of missing collaboration between the spin-off and relevant business units from the main organization (Markides 2013).

Furthermore, when designing a DT strategy, organizations need to decide on the locus of authority to plan concerning the execution of such decisions. Following Mihalache et al. (2014) and Wong et al. (2011, p. 1210), the centralization of decision-making "occurs when decision-making power resides in the hands of a selected few at the upper levels of an organization, whereas decentralization occurs when decisionmaking power involves individuals at various organizational levels". Various organizational science scholars highlight the advantages of decentralized decision-making (Mihalache et al. 2014; Jansen et al. 2006). Such an approach may strengthen the responsiveness and flexibility of an organization due to a decrease in information decay, caused by the exchange of information between different levels of hierarchy (Mihalache et al. 2014). Thus, this may also enable a higher degree of local control over IT systems since these can more easily be adapted to the individual needs of different internal stakeholders (Huang et al. 2010). Furthermore, for locally organized customer relationships, centralization leads to corporate dissonance which is often resolved by shifting the responsibility to lower-level managers since they are closer to the customer (Sklyar et al. 2019). On the other hand, IS scholars oftentimes recommend centralized decision-making, especially for DT strategies (Horlacher et al. 2016). Recently, there is increasing evidence of the effectiveness of introducing CDOs (Singh and Hess 2017). They are usually part of the management board since they need sufficient opportunities to influence DT-related decisions. However, in organizations in which business departments are in charge of innovation management, CDOs may not be needed or may even have a detrimental effect (Leonhardt et al. 2018). Oftentimes, DT strategies are also managed by a cross-functional steering committee of key executives, sometimes called a "digital committee" (Haffke et al. 2016; Chanias et al. 2019). This committee often replaces the role of the $\mathrm{CDO}$, sharing the responsibilities among the members, but may also be formed in parallel (Haffke et al. 2016). A smaller number of people who are involved in decision-making is associated with an increase of decision-making speed and decisions that challenge the status quo and therefore lead to higher innovation performance (Teece 1996). Furthermore, a centralized approach also enables stricter global control over IT systems (Brown and Grant 2005). This, in turn, leads to a reduction of uncertainty through earlier planning, without the need to involve several decision-makers or to follow decision processes that may be too complex (Reynolds et al. 2010). In the context of DT, centralized decision-making may also lead to higher digital innovation performance when an organization is faced with a highly turbulent environment (Leonhardt et al. 2018). In summary, while extant research agrees that the locus of decision-making is a success factor for organizational transformation, it differs in how centralized it should be.

Typically, established organizations will have extensive know-how on their existing products and processes, but their capabilities for executing DSI will vary. Equally, they have different options for acquiring these capabilities: they may opt to acquire these capabilities internally ("insourcing") or engage in strategic outsourcing through alliances and partnerships to externally acquire the necessary innovation capabilities (Vial 2019). To insource, organizations may choose to train their established workforce to turn them into co-creators of DT (Müller and Renken 2017) or they may extend their workforce by hiring employees that bring the required capabilities into the organization (Teece 1996). Additionally, acquiring 
other organizations may have a positive effect on innovation processes if the acquired companies have relevant digital innovation capabilities (Hildebrandt et al. 2015). However, the importance of outsourcing and building strategic partnerships for DSI has grown over the last few years since building up capabilities internally may not be feasible for many organizations. Diverse entities such as "competitors, suppliers, customers, end-users, universities, or public research institutions" may serve as partners for DSI (Hottenrott and Lopes-Bento 2016, p. 778). Engaging in partnerships leads to higher dynamic adjustability and scalability of a firm's assets and competencies (Bouncken and Fredrich 2016; Hottenrott and Lopes-Bento 2016). Strategic outsourcing played a significant role in LEGO's digital strategies by complementing their existing capabilities (El Sawy et al. 2016). Furthermore, collaboration helps to reduce internal resistance to innovation as well as creating an agile mentality and working culture (Piccinini et al. 2015). Still, a high collaboration intensity may also lead to a negative impact on innovation performance (Hottenrott and Lopes-Bento 2016). In particular, long partnership durations affect performance negatively since they "might drive misalignment of partners, breed strong conflicts, or opportunism tactics about value capture" (Bouncken and Fredrich 2016, p. 3588). Furthermore, organizations disclose internal knowledge to external parties, which carries certain risks with it. Therefore, the decision of how and to what extent to engage in strategic outsourcing and how this affects innovation performance depends on different factors.

So far, the literature has hardly investigated the effectiveness of DT strategies and their influence on the desired outcomes, such as the effectiveness of service innovation, at all. This limitation is also acknowledged by scholars: Berghaus and Back (2017, p. 14), for example, state that they "cannot make any remarks on one approach being more successful than another". Matt et al. (2015, p. 342) noted that research on DT strategies would benefit from "comparing digital transformation strategies across different industries [...] in order to increase success rates". DT strategies are often regarded as successful if they are implemented as planned, but without measuring the results (Singh and Hess 2017; Hess et al. 2016). A notable exception is the work of Leonhardt et al. (2018), who use a quantitative measure for assessing digital innovation performance. Their results highlight the importance of centralized decision-making in turbulent environments and the potentially detrimental effects of CDOs when business departments are responsible for digital innovation. Furthermore, they show that turbulent environments generally favor innovation performance, which may suggest a positive effect of competitive threats in the context of DT. However, the analysis does not consider other factors such as outsourcing or structural separation.

\subsection{Research Framework}

In this paper, we focus on explaining what combinations of DT strategies lead to successful and unsuccessful DSI. As DT strategy building blocks, we choose three different elements building on the presented literature review: structural separation, strategic outsourcing, and the centralization of decisionmaking. Furthermore, we include a contextual variable: the threat of digital disruption for a specific company by new market-entrants (Skog et al. 2018). DT strategies are formulated and executed to counter this threat which is why we expect these strategies to be different depending on how threatened companies are in their respective industries (Skog et al. 2018; Leonhardt et al. 2018). For instance, retailers are already suffering the consequences of digital disruption (Gilbert 2015). However, other industries such as highly specialized manufacturing might not perceive any digital disruption because they are subject to a low level of competition. We argue that due to the complexity of DT, there may not be only one path to success. Furthermore, there may be multiple interdependencies between the building blocks of a DT strategy: for example, a high degree of strategic outsourcing might require better and stricter control through centralized decision-making to keep track of the different implementation efforts. On the other hand, a low degree of structural separation may favor a decentralized approach that allows better local control.

To answer the research question at hand, we adopt configuration theory as our theoretical perspective. Configuration theory proposes that "organizational phenomena can best be understood by identifying distinct, internally consistent sets of firms and their relationships to the environment and performance outcomes" (Ketchen et al. 1997, p. 224). Traditional variance-based theories postulate that predictor variables are both necessary and sufficient conditions for predicting a certain outcome (Liu et al. 2015; El Sawy et al. 2010). Furthermore, they assume that the relationship between the outcome and a predictor variable is always symmetric (Liu et al. 2015). Configuration-based theories allow for asymmetric relationships between predictors and the outcome since they "view phenomena as clusters of interconnected elements that must be simultaneously understood as a holistic integrated pattern" (El Sawy et al. 2010, p. 838). In particular, this means that a predictor could be sufficient for a specific outcome, but not necessary. It also means that the interplay of different predictors leads to a specific outcome and that this interplay can be depicted through different configurations of predictors. This follows the concept of equifinality, which states that a system can reach a specific state through different paths and different initial conditions (Gresov and Drazin 1997). The 
characteristics of configuration-based theories make them especially suited to build middle-range theories in specific contexts (El Sawy et al. 2010; Park et al. 2017). While variancebased approaches require the researcher to formulate specific hypotheses regarding the relationships of the variables in question beforehand, configurational theories allow for a more exploratory research design. The researcher can identify potentially relevant theoretical constructs based on relevant literature, distill patterns leading to a specific outcome, and afterward return to the literature by theorizing based on the identified patterns (Park et al. 2017). We propose that this approach is especially well-suited to the context of our research question since recent literature on the relatively new field of DT strategies provides plenty of avenues for exploratory research designs. Figure 1 summarizes our proposed research framework. By using a Venn diagram, we denote the configurational perspective that we adopt to answer our research question. On the left side, we show the different antecedents that interact with each other to account for the outcome on the right side of the figure.

\section{Research Approach}

\subsection{Data Collection}

We employed a comparative case analysis approach to answer our research question to benefit from advantages such as being able to use additional data from the cases during and after analysis in an iterative way (Ragin 2008). We selected a purposive theoretical sampling strategy based on certain criteria since our goal was to investigate cases "that exhibit the phenomenon at hand in order to look for commonality (i.e. the presence or absence) of the outcome in the configurations of conditions across cases" (Tóth et al. 2017, p. 194). First, we aimed to find established companies to which we refer as companies whose key products and services were established at the latest shortly after the dot-com bubble and who are still active in this market. Second, the company needed to already have launched a DT strategy. Third, this strategy needed to be aimed at developing DSI and offering digital services in addition to existing products and services. We identified initial candidate companies through an internet search and contacted representatives with the request to carry out a case study. Eventually, we were able to carry out exploratory, in-depth case studies with 17 organizations from different industries. Table 5 in the appendix provides an overview of the cases with additional information. The interviewees included positions such as executives (CEO, CIO, CDO, and others), project managers, or business unit leaders. In most of the cases, top executives at the organization provided us with a set of interviewees who were involved in the respective DT strategies. These interviewees, in turn, oftentimes suggested followup interviews with other employees. We employed semistructured interview guidelines covering the central issues of the respective DT strategies. At the same time, we gained insights during the interviews through follow-up questions that were not directly covered by the initial guideline. As an initial data source, several organizations granted us access to their confidential materials such as internal reports, strategy presentations, or market analyses, or anonymized or aggregated customer data. Finally, we consulted publicly accessible material such as company websites to triangulate our findings from the interviews and document analyses.

Our data analysis approach followed both an inductive and a deductive approach. First, we engaged in open coding of our data sources to identify potential antecedents of successful or unsuccessful DSI (Corbin and Strauss 1990). The coded material was then clustered following an axial coding approach, resulting in higher-order themes. Afterward, we performed

Fig. 1 Research framework

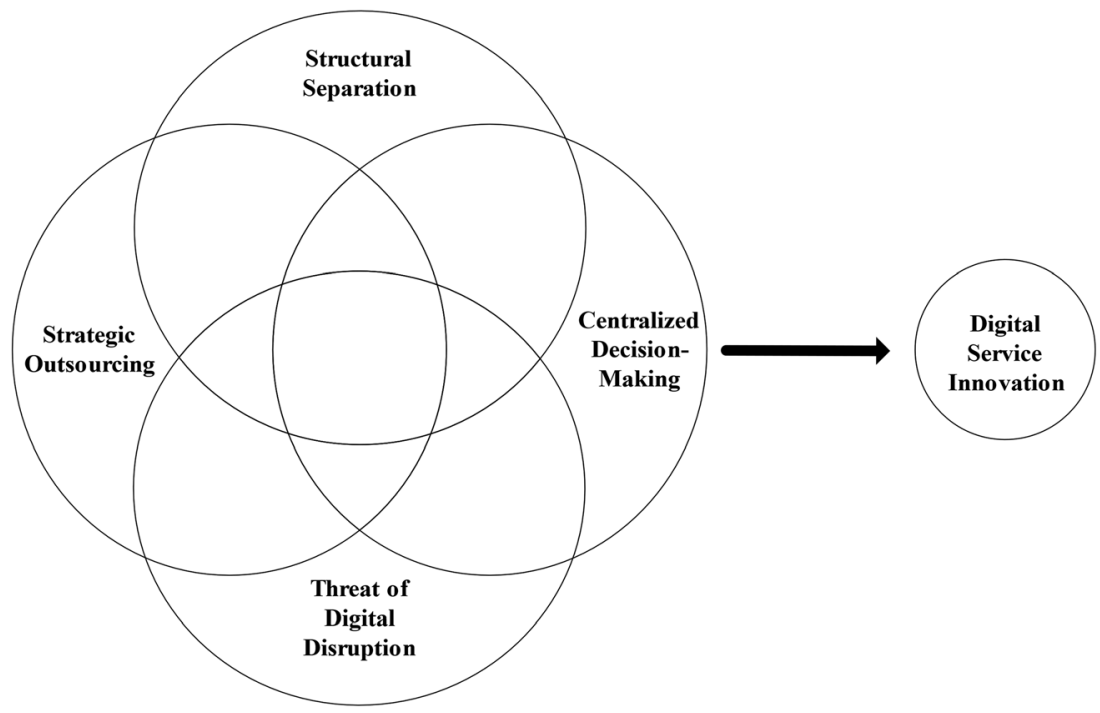


backward coding to cover potentially overlooked themes by engaging in an iterative coding process. Finally, we linked our higher-order themes to our eventual research framework. We used the qualitative data analysis software Atlas.ti during our coding process. Furthermore, we carried out respondent validation of our findings from the case organizations. We performed a member-check procedure by presenting our insights and interpretations of the cases to selected interviewees (Lee and Baskerville 2003). Usually, this was followed by valuable exchanges of perception that led to additional knowledge and insights used in our main analysis.

\subsection{Fuzzy-Set Qualitative Comparative Analysis}

To derive DT strategy configurations, we employed fsQCA, a set-theoretic configurational approach. While fsQCA is well suited for small to medium-sized samples (11-50 cases) as well as for large samples (>50 cases), its aims and potential contributions may vary (Greckhamer et al. 2018). When performed on large samples, it can be used for both theory building and testing with the possibility to draw statistical inferences (Greckhamer et al. 2013). Small samples, on the other hand, are particularly well-suited for inductive reasoning and theory building due to a higher familiarity with the cases (Greckhamer et al. 2013). It should furthermore be noted that fsQCA uses an approach known as "modest generalization" (Berg-Schlosser et al. 2009, p. 12). This means that a researcher can build propositions based on an fsQCA and then apply them to cases sharing similar characteristics (Berg-Schlosser et al. 2009). On the one hand, this may be a more limited approach than the one used by regression-based methods since it is more difficult to generalize based on a whole population. On the other hand, this approach is also more robust than drawing generalizations from multiple-case studies with even smaller datasets. In our study, we opted for a small-sized sample since we were mainly interested in theory building due to the scarcity of previous research. FsQCA consists of three subsequent steps: assignment of fuzzy-set membership scores to cases (also known as calibration), identification of necessary conditions, and identification of sufficient configurations (Ragin 2009). We used the fsQCA R package to complete all three steps (Duşa 2019). Table 1 provides an overview of our causal conditions and the outcome along with definitions and selected key sources based on the framework derived in the preceding section. Although the threat of digital disruption cannot be actively controlled by an organization, we include it as an element of potential configurations since we expect them to vary depending on the degree of the threat.

FsQCA uses fuzzy-set membership scores ranging between 0 and 1 to determine the degree to which a case is a member of a set (Ragin 2008). For each case and each dimension/outcome, a fuzzy-set membership score is assigned during the calibration phase (Ragin 2008).
Procedures for calibration typically vary with the sample size. Analyses with large samples are most prevalent in IS and business and management research and are typically combined with questionnaire-based surveys or other quantitative data (Soto Setzke et al. 2020; Wagemann et al. 2016). Calibrating this data is often straightforward and includes choosing appropriate thresholds for Likert scales or quantitative data. Smaller sample sizes, on the other hand, typically involve a considerable amount of qualitative, unstructured data. Calibration of this data is quite challenging since few guidelines can be followed and the results may suffer from subjectivity (de Block and Vis 2019). Therefore, several methodological articles providing guidelines regarding the calibration of qualitative data have been published over the last years (see, e.g., Basurto and Speer (2012); Tóth et al. (2017); Nishant and Ravishankar (2020)).

For this paper, we adopted the methodological guidelines proposed by Basurto and Speer (2012) and closely followed an exemplary application by Iannacci and Cornford (2018). To calibrate data collected through interviews, they suggest the use of "theoretical ideals" as "the best imaginable case in the context of the study that is logically and socially possible" (Basurto and Speer 2012, p. 166). We defined two ideal cases per condition: a "fully in" case that represents definite full membership in the set and (fuzzy value of 1) a "fully out" case that represents definitive non-membership (fuzzy value of 0 ). Based on these ideal types, we defined a threshold condition that served as our indicator for deciding for or against inclusion in the set. Lastly, we defined how much a case could deviate from a "fully in" or "fully out" case without passing the threshold. Based on these definitions, we assigned fuzzy values 0.33 and 0.66 , thus using a fuzzy 4 -value scheme (Tóth et al. 2017). Based on the summary statements of the cases, each case can be calibrated according to the previously proposed ideal types. In the following, we explain our rationale for creating "fully in" and "fully out" cases as well as the threshold conditions.

Structural separation: as our ideal "fully in" case, we defined an organization that completely separated its innovation activities into one or more spin-off organizations. To distinguish the relationship between the main organization and spin-offs from partnerships with external organizations, we account for the fact that these innovation activities may still partly be coordinated by the main organization. For our "fully out" case, no new structures should have been created, neither in the form of spin-offs nor internal units. As a threshold, we chose the condition that spin-offs were created since they demark a major structural separation from the core business (Corley and Gioia 2004). Therefore, smaller structural changes such as creating new digital business units were counted as being more out than in, while creating spin-offs that were still 
Table 1 Overview of coding elements

\begin{tabular}{|c|c|c|c|}
\hline Element & Theoretical construct & Definition & Key sources \\
\hline \multirow[t]{4}{*}{ Causal conditions } & Structural separation & $\begin{array}{l}\text { Separation of innovation-related activities in- } \\
\text { to distinct organizational units }\end{array}$ & $\begin{array}{l}\text { Matt et al. (2015), Corley and Gioia(2004), } \\
\text { Teece (1996) }\end{array}$ \\
\hline & Centralization of decision-making & $\begin{array}{l}\text { "Decision-making power resides in the hands } \\
\text { of a selected few at the upper levels of an } \\
\text { organization" (Wong et al. 2011, p. 1210) }\end{array}$ & $\begin{array}{l}\text { Jansen et al.. (2006), Mihalache et al. (2014), } \\
\text { Wong et al. (2011), Guadalupe et al. } \\
\text { (2014) }\end{array}$ \\
\hline & Strategic outsourcing & $\begin{array}{l}\text { Reliance of an organization on external } \\
\text { partnerships to carry out service innovation }\end{array}$ & $\begin{array}{l}\text { Hottenrott and Lopes-Bento (2016), Teece } \\
\text { (1996), Vial (2019), Bouncken and } \\
\text { Fredrich (2016) }\end{array}$ \\
\hline & Threat of digital disruption & $\begin{array}{l}\text { Threat to the core business of an organization } \\
\text { posed by new/established market entrants } \\
\text { using digital technologies }\end{array}$ & $\begin{array}{l}\text { Skog et al. (2018), Matt et al. (2015), } \\
\text { Leonhardt et al. (2018) }\end{array}$ \\
\hline Outcome & Digital service innovation & $\begin{array}{l}\text { Successful introduction of new services based } \\
\text { on digital technologies }\end{array}$ & $\begin{array}{l}\text { Barrett et al. (2015), Goduscheit and Faullant } \\
\text { (2018) }\end{array}$ \\
\hline
\end{tabular}

mainly controlled by the main organization were calibrated as more in than out.

Centralization of decision-making: in our ideal "fully in" case, decision-making is entirely centralized in one executive at the highest management level, i.e. the "C-suite". Our "fully out" case is characterized by a team lead or no specific role at all. Building upon these cases, we defined the threshold to indicate whether decision-making is done in the C-suite or at a lower management level (Guadalupe et al. 2014). Therefore, cases, where a manager or a business unit leader is responsible, were coded as more out than in. Accordingly, cases where a team of different C-level executives and, potentially, managers were responsible, were coded as "more in than out," since these are part of the C-suite but represent a lower degree of centralization.

Strategic outsourcing: Our "fully in" case represents organizations that rely completely on external partnerships while our "fully out" case represents organizations that do not rely on external partnerships at all. Since partnerships are very common for implementing DT strategies (Vial 2019), we concluded that, apart from the "fully out" case, partnerships would very likely be a part of the majority of DT cases. Thus, we decided to let the threshold indicate to what degree partnerships are used. We coded cases as more out than in if partnerships were used only to implement certain key aspects, but the main effort was still done by the main organization. Accordingly, if the effort was distributed differently, we coded the case as more in than out.

Threat of digital disruption: In the "fully in" case, organizations face an imminent threat of being disrupted while in the "fully out" case, they do not face any considerable threats of disruption in the foreseeable future. We decided to use the timeframe of potential disruption as a threshold: organizations that may face disruption in the long term (5-10 years) were coded as more out than in, while organizations, where disruption may be relevant in the short term (3-5 years), were coded as more in than out.
Digital service innovation: Our "fully in" case represents radical service innovations that are new to the respective industry while our "fully out case" represents cases where ultimately, no new services were launched. Since we are interested in radical innovation, we decided to use the notion of radical innovation as our threshold. If new services had been introduced but they represented mostly incremental improvements of already existing service concepts, they were coded as more out than in. On the other hand, if the organization introduced rather radical services, we classified them as more in than out. Accordingly, for our outcome, we define radical innovation as successful and incremental innovation as unsuccessful.

To facilitate the coding process, we prepared summary statements for each case along with relevant quotes for each dimension. It should be noted that some distinctions may seem subjective and difficult to code, particularly the fine-grained edge cases between fully and more out than in as well as fully in and more in than out. To mitigate this potential imprecision introduced by subjectivity, two authors and another researcher independently calibrated each condition and the outcome for each case, using the ideal types and the respective fuzzy values. Afterward, we assessed interrater reliability for each dimension among all cases by using Krippendorff's alpha, a measure that checks for chance coincidences (Krippendorff 2018). After coding, interrater reliability exceeded the most conservative threshold of 0.8 for all dimensions. Still, differences in assigned membership scores remained. The researchers then resolved these differences through oral discussion (Krippendorff 2018). For the case Kappa and the condition "Centralization of decision-making", for example, two researchers assigned a fuzzy value of 0.33 and one assigned a value of 0.66 . The discussion then revolved around a quote in which the project lead of the DT strategy stated that he reports to the executive board of Kappa to ensure support for the strategy. During coding, the third researcher concluded that therefore, at least one $\mathrm{C}$-level executive was responsible 
for the strategy (i.e., a fuzzy value of 0.66). However, the two other researchers argued that the project lead was merely reporting and ensuring support to secure resources for strategy implementation, but the main responsibility was still assigned to the project lead (i.e., a fuzzy value of 0.33 ). Eventually, the third researcher was convinced and all three agreed on using a fuzzy value of 0.33 .

To provide transparency, we provide additional information on the coding process in the appendix. Appendix Table 6 provides a detailed overview of our ideal cases and the conditions that were used to assign fuzzy values based on extant literature along with the value of Krippendorff's alpha for each dimension. An illustrative example of how fuzzy-set membership scores were assigned to the condition "strategic outsourcing" is shown in Appendix Table 7. Furthermore, Appendix Table 8 shows an example of how case Rho was calibrated. A full overview of membership scores for all cases and dimensions can be found in Appendix Table 9. All other data is available upon request from the authors.

Necessary condition analysis reveals conditions that are present in every case; thus, resulting in a specific outcome. More specifically, this means that the fuzzy-set membership score of the outcome in each case is less than the score of the necessary condition (Schneider and Wagemann 2012). To be considered a necessary condition, a consistency threshold of at least 0.9 should be reached (Schneider and Wagemann 2012). Consistency refers to the degree to which cases with the same conditions share the same outcome (Ragin 2008). Furthermore, the coverage value (i.e., the proportion of the outcome covered by a specific condition) should be assessed for each necessary condition to determine its empirical relevance (Schneider and Wagemann 2012). While necessary conditions are always present when a specific outcome occurs, the condition could also be present while the outcome is not (Ragin 2008). Thus, we proceeded to identify sufficient configurations.

Sufficiency analysis reveals configurations of conditions that guarantee a specific outcome if present in a case (Ragin 2008). Unlike necessary conditions, however, a specific configuration does not always have to be present to produce the outcome. Thus, there can be multiple configurations leading to the same outcome. We first constructed two truth tables showing all $16\left(2^{\mathrm{k}}\right.$, where $\mathrm{k}$ equals the number of conditions) possible configurations of conditions for both outcomes (see Tables 10 and 11 in the appendix). Afterward, we reduced the table by applying the threshold of frequency, raw consistency, and PRI consistency. Since our sample of 17 cases can be classified as medium-sized, we employed a frequency threshold of one (Greckhamer et al. 2013). Thus, configurations that are represented by at least one empirical observation are kept in the truth table. For the raw consistency threshold, we chose a value of 0.85 , exceeding the widely accepted conservative threshold of 0.75 (Schneider and Wagemann 2012). As described before, raw consistency assesses the degree of how reliably a configuration results in the outcome and can roughly be compared to the notion of significance in regression analysis (Park et al. 2017). PRI consistency is an alternative consistency measure that "eliminates the influence of cases that have simultaneous membership in both the outcome and its complement" (Park et al. 2017). While there is currently no widely accepted threshold of PRI consistency, we followed the guidelines from Schneider and Wagemann (2012) and apply a threshold of 0.65 . Having reduced the truth table by applying thresholds of frequency, raw consistency, and PRI consistency, we applied the Quine-McCluskey algorithm to further reduce and simplify the remaining truth table. Afterward, we were left with configurations of conditions that lead to our outcome in question (Ragin 2008).

Finally, researchers should test for predictive validity, which "examines how well the model predicts the outcome in additional samples" (Pappas et al. 2017, p. 674; Woodside 2014). While a model may exhibit high values of consistency and coverage for a given sample, this does not necessarily mean that it is also able to make good predictions. To perform the test, the sample is first divided into a subsample and a holdout sample. The researcher then runs the analysis against the subsample and recodes all resulting configurations as a new variable. Each configuration variable is then plotted against the outcome of interest using the holdout sample. To guarantee high predictive validity, the resulting consistency and coverage should not contradict the values from the solution (Pappas et al. 2017).

\section{Results}

\subsection{Necessary Condition Analysis}

The results of our necessary condition analysis (Table 2) reveal that centralization of decision-making is the only necessary condition for achieving DSI since it exceeds the consistency threshold of 0.9 and, with a coverage level of 0.7 , explains a considerable part of the outcome (Ragin 2008). Apart from this, no other condition reaches the minimum threshold of 0.9 . We thus conclude that centralized decision-making needs to be part of a DT strategy to succeed and that it is the only necessary condition from our set of candidate conditions. However, even if centralized decision-making is in place, DT strategies can still fail. Thus, we now proceed to present the results of the sufficiency analysis.

\subsection{Sufficiency Analysis}

Our sufficiency analysis yielded an intermediate solution with five configurations that explain successful and unsuccessful 
Table 2 Necessary conditions for digital service innovation

\begin{tabular}{|c|c|c|c|c|}
\hline \multirow[t]{2}{*}{ Conditions } & \multicolumn{2}{|c|}{ Successful digital service innovation } & \multicolumn{2}{|c|}{ Unsuccessful digital service innovation } \\
\hline & Consistency & Coverage & Consistency & Coverage \\
\hline Structural separation & 0.61 & 0.71 & 0.65 & 0.63 \\
\hline Centralization of decision-making & 1.00 & 0.70 & 0.86 & 0.50 \\
\hline Strategic outsourcing & 0.71 & 0.67 & 0.78 & 0.60 \\
\hline Threat of digital disruption & 0.39 & 0.65 & 0.56 & 0.77 \\
\hline$\sim$ Structural separation & 0.68 & 0.70 & 0.70 & 0.60 \\
\hline$\sim$ Centralization of decision-making & 0.29 & 0.72 & 0.48 & 1.00 \\
\hline$\sim$ Strategic outsourcing & 0.58 & 0.76 & 0.57 & 0.62 \\
\hline$\sim$ Threat of digital disruption & 0.86 & 0.70 & 0.74 & 0.50 \\
\hline
\end{tabular}

$\sim$ logical NOT; Necessity consistency threshold: 0.9

DSI. When deriving the intermediate solution, we employed the simplifying assumption that centralized decision-making has a positive impact on the outcome and a negative impact on the negative outcome. All five resulting configurations are displayed in Table 3. Following the fsQCA convention, black circles denote the presence of a condition while crossed-out circles indicate its absence. Blank spaces indicate that the condition is not relevant for explaining the outcome. Furthermore, large circles denote core conditions with high empirical relevance while small circles represent peripheral conditions that surround core conditions (Fiss 2011). Our proposed solutions show consistency levels of 0.91 and 0.92 , which are well above the level of 0.8 which is commonly considered acceptable in QCA research (Ragin 2008). Similarly, our solution coverage levels of 0.75 and 0.52 show that we can explain a considerable share of both outcomes.

As Table 3 shows, we identified two configurations for DT strategies that lead to successful DSI. The first configuration (A1) represents organizations that achieve DSI by organizing innovation activities in spin-offs, involving C-level executives in governing their strategy, and relying on partnerships to implement the strategy. For this configuration, it does not matter whether the organization is facing a threat of digital disruption. The second configuration (A2) depicts organizations where Clevel executives are involved in DT strategy governance. However, they implement aspects of the DT strategy mostly on

Table 3 Sufficient configurations for digital service innovation

\begin{tabular}{|c|c|c|c|c|c|}
\hline \multirow{2}{*}{ Causal conditions } & \multicolumn{2}{|c|}{ Successful digital service innovation } & \multicolumn{3}{|c|}{ Unsuccessful digital service innovation } \\
\hline & A1 & A2 & B1 & B2 & B3 \\
\hline Structural separation & & & & 0 & \\
\hline Centralization of decision-making & & 0 & $\bigotimes$ & & $\bigotimes$ \\
\hline Strategic outsourcing & & $\bigotimes$ & & $\bigotimes$ & $\bigotimes$ \\
\hline Threat of digital disruption & & $\bigotimes$ & & & \\
\hline Consistency & 0.87 & 0.99 & 1.00 & 0.89 & 1.00 \\
\hline Raw coverage & 0.46 & 0.54 & 0.17 & 0.34 & 0.26 \\
\hline Unique coverage & 0.21 & 0.29 & 0.04 & 0.21 & 0.13 \\
\hline Solution consistency & \multicolumn{2}{|c|}{0.91} & \multicolumn{3}{|c|}{0.92} \\
\hline Solution coverage & \multicolumn{2}{|c|}{0.75} & \multicolumn{3}{|c|}{0.52} \\
\hline
\end{tabular}

Black circle presence of a condition, Crossed-out circle absence of a condition, Empty row may be either present or absent, Large circle core condition, Small circle peripheral condition; Raw consistency cut-off: 0.85; PRI consistency cut-off: 0.65 ; Frequency cut-off: 1 
their own and are not facing any imminent threat of digital disruption. Here, it does not matter whether the organization organizes its innovation activities in spin-offs.

We found three distinct configurations for unsuccessful DSI. The first configuration (B1) shows organizations where team/ business unit leads or managers are mostly responsible for governing the strategy as opposed to C-level executives. Additionally, these organizations face an imminent threat of digital disruption and conduct innovation activities in spin-offs. The second configuration (B2) depicts organizations that also face an imminent threat of digital disruption and additionally implement key aspects of the DT strategy mostly on their own as opposed to relying on partnerships. As in $\mathrm{B} 1$, these organizations have a high degree of structural separation. The third configuration (B3) combines the core conditions of B1 and B2: low degrees of centralized decision-making and strategic outsourcing and a high degree of threat of digital disruption.

Furthermore, we tested for predictive validity to identify whether our model can be used to predict the outcome in additional samples (Woodside 2014; Pappas et al. 2016). To do so, we randomly divided the sample into a subsample and a holdout sample. We then performed the analysis for the subsample and tested the result against the holdout sample. Table 4 demonstrates that the patterns obtained from the first analysis consistently indicate successful and unsuccessful DSI. We then plotted all four models against the outcome variable. Figure 2 illustrates the findings for testing model 1 against the outcome of successful DSI with the holdout sample and exhibits high degrees of consistency (0.966) and coverage (0.47). Similarly, Fig. 3 illustrates the results of plotting model 3 against the negation of the outcome and shows high consistency (0.75) as well as coverage (0.21). We, therefore, conclude that the highly consistent models from the subsample are consistent predictors for the holdout sample. Detailed results are available upon request.

\section{Discussion}

\subsection{Observations and Patterns across Configurations}

Our analyses reveal that centralization of decision making is a necessary condition for successful DSI and that there are multiple configurations of DT strategies that lead to either successful or unsuccessful DSI. We will now highlight certain particularities and patterns that can be observed across the identified configurations and compared them with observations from previous research. Throughout our discussion, we will refer to the configurations by using the codes introduced in Table 3 (A1, A2, B1, B2, and B3).

Interestingly, our results show that an imminent threat of digital disruption is a decisive element leading to both success and failure. While the absence of this threat is associated with success in one configuration (A2), the threat's presence is a part of all three configurations associated with failure (B1, B2, and B3). Previous research shows that the threat of disruption or competitive pressure can impact an organization's ability both positively (Amabile et al. 2002; Sheremata 2000) and in an ambivalent way, depending on the context of the competitive situation (Beneito et al. 2015; Ismail 2015; Amabile et al. 2002). The results from our analysis depict competitive pressure in a rather negative way. For instance, case company Rho states that they are under a high amount of pressure since their "current business is stopping in a few years" and their "biggest worry" is whether they can transform their core business fast enough. However, their DT initiative has been focused rather on internal process innovation and less on developing and introducing new business models and services, thus increasing pressure. Case company Kappa, a traditional business-tobusiness hardware seller, is also facing severe competition resulting in drastically reduced turnover due to rival online platforms. However, their online platform is focused on

Table 4 Complex configurations indicating successful and unsuccessful digital service innovation

\begin{tabular}{lccc}
\hline & Consistency & Raw coverage & Unique coverage \\
\hline Models from subsample for successful DSI & & & 0.23 \\
$\mathrm{SSE}^{*} \mathrm{CDM}^{*} \sim \mathrm{TDD}$ & 0.89 & 0.61 & 0.16 \\
$\mathrm{CDM}^{*} \sim \mathrm{SOS}^{*} \sim \mathrm{TDD}$ & 0.99 & & \\
Overall solution consistency & 0.91 & & 0.39 \\
Overall solution coverage & 0.77 & 0.49 \\
Models from subsample for unsuccessful DSI (negation) & 0.30 \\
SSE* CDM* $\sim$ SOS*TDD & 1.00 & & 0.20 \\
$\sim$ SSE* CDM $\sim$ SOS*TDD & 1.00 & & \\
Overall solution consistency & 1.00 & 0.69 & \\
Overall solution coverage & & \\
\hline
\end{tabular}

SSE structural separation, $C D M$ centralized decision-making, SOS strategic outsourcing, $T D D$ threat of digital disruption, $D S I$ digital service innovation. 
Sufficiency relation

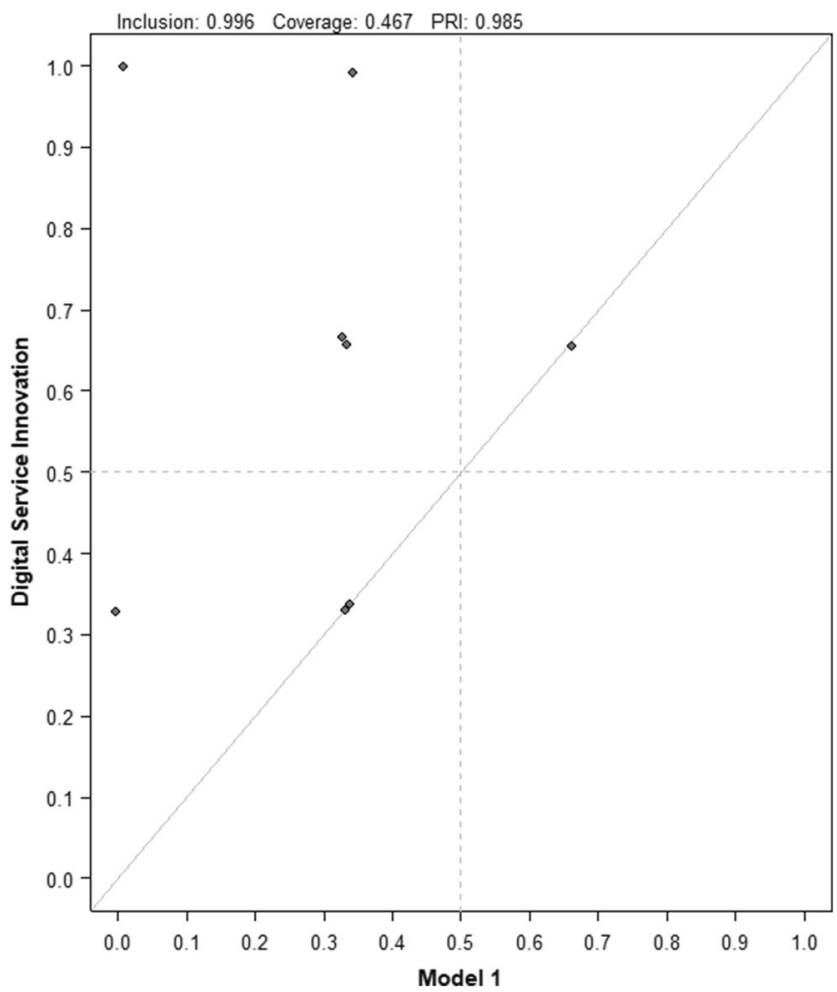

Fig. 2 Predictive validity test of Model 1 from subsample using data from the holdout sample for successful digital service innovation

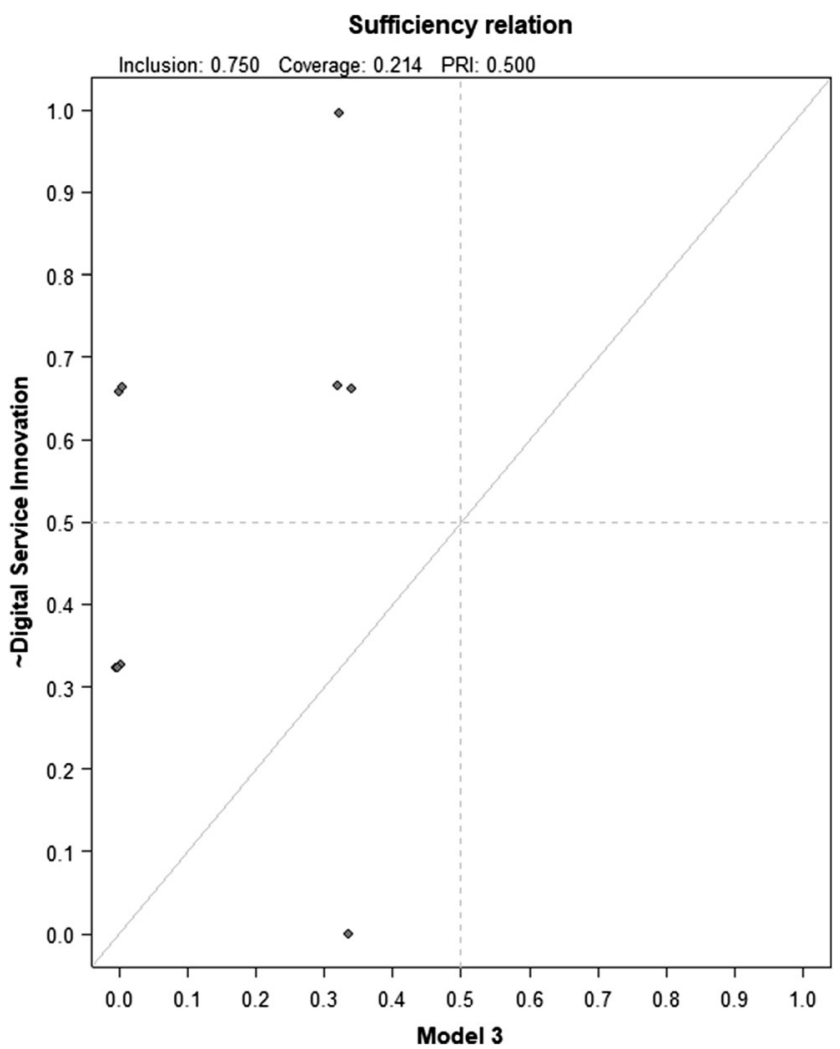

Fig. 3 Predictive validity test of Model 3 from subsample using data from the holdout sample for unsuccessful digital service innovation supporting existing sales processes and suffers from poor adoption by both customers and sales employees. Still, we propose that even companies under pressure can succeed at DSI given the right circumstances since the absence of the threat of digital disruption is not a necessary condition for success in the results of our analysis nor is the presence of threat a necessary condition for failure. A possible solution is depicted in configuration A1: companies that implement an approach based on spin-offs, centralized decision-making, and strategic partnerships succeed irrespective of the amount of external pressure.

The role of partnerships in implementing DT strategies warrants further discussion in the context of the threat of digital disruption. The results show that organizations under threat fail at DSI when they do not (or only partly) engage in strategic implementation partnerships (B2). On the other hand, a "do-it-yourself" approach seems appropriate when organizations perceive no or very little threat and employ a centralized decision-making approach (A2). We thus conclude that organizations that are not under pressure have enough time to experiment and build up their resources such as information technology infrastructure or software developers. Case company $\mathrm{Pi}$, for instance, is a world leader in industrial manufacturing. Given its excellent competitive position in the market, the threat of digital disruption is very low for Pi. Consequently, Pi had enough time to build a spin-off and hire a lot of software developers who designed and implemented an industrial Internet of Things (IoT) platform, with little external assistance. If $\mathrm{Pi}$ had been under higher pressure to transform itself in a short amount of time, it may not have been possible for the company to take its time and implement its strategy mostly on its own. It is important to note that the decision to engage or not engage in partnerships in consideration of impending pressure is sometimes also taken due to this pressure. Case company Iota, for example, finds itself in a competitive environment and does not engage in partnerships. In the results, Iota is covered by configuration B2. An interviewee at Iota stated his belief that "Iota does not dare to engage in partnerships yet" because "Iota does not dare to trust that someone else can bring us benefits and not damage us in some way". Thus, we propose that organizations need to learn how to engage in healthy partnerships that do not threaten the organization's core business but rather benefit both sides. Recent research on DT highlights the importance of ecosystemic thinking and strategizing, especially when it comes to service innovation (Lusch and Nambisan 2015). While organizations that are well-positioned on the competitive field may succeed in innovation-related activities on their own for now, it is unclear whether a rather egoistic perspective will also succeed in sustaining this position.

The necessary condition analysis shows that centralization of decision making is a prerequisite for successful DSI. In particular, this means that organizations need a $\mathrm{C}$-level executive to 
govern the DT strategy or form a digitalization committee where at least one $\mathrm{C}$-level executive is involved. This confirms previous research that highlights the importance of top management team (TMT) energy in organizational change processes, especially in IS-enabled change projects (Park et al. 2017; Tronvoll et al. 2020). Case company Kappa is an illustrative example of an organization where the TMT is not heavily involved. In Kappa, the DT strategy is mainly steered by a business unit leader who reports to the top management board that approves, for example, budget requests, but is not as heavily involved in leading the strategy. Similarly, in the case of company Rho, a business unit leader is responsible for the DT strategy, stating that the "managers who approve our business cases typically do not know in detail what is actually needed for them". Furthermore, he stated that he "need[s] to make the management aware of every step that is needed to, get features live which can be monetized in the end for Rho". Thus, we propose that a DT strategy requires top management attention and needs to be governed by C-level executives to be successful.

\subsection{Theoretical Contributions}

This paper contributes to theory in several ways. First, it adds to the growing literature on DSI and DT and is one of the first studies that integrate these two perspectives to paint a more complete picture. As outlined in the theoretical background to this paper, the literature on DSI has mainly focused on effective processes, use cases, or the characteristics of innovations. By regarding DT strategy building blocks as antecedents of DSI, we add a new perspective to explain how effective DSI can be established. On the other hand, the literature on DT strategies has rarely explored the actual outcome and effectiveness of these strategies. Therefore, we add an outcome-oriented perspective to this relatively young literature stream. We also contribute individually to each research stream, addressing research gaps such as effective organizational changes for service innovation (Biemans et al. 2016) or the success patterns of DT strategies (Matt et al. 2015).

Second, we provide a perspective on the ways DSI can fail. While current literature focuses predominantly on successful service innovation, only a few studies have explicitly investigated innovation failure (see, for example, Dudau et al. (2017); Weber et al. (2011); Dörner et al. (2011); Goduscheit and Faullant (2018)). Furthermore, while some of these studies note the importance of digital technologies, they focus on other enablers such as individual attitudes and behavior or other units of analysis such as entire industries. Our results provide the first insights into the characteristics of DT strategies that lead to DSI failure as well as different avenues for future research.

Third, we employed a configurational research approach to answer our research question. By doing so, we follow several calls for research from both DT literature (Riasanow et al. 2019) as well as service innovation (Kohtamäki et al. 2019; Goduscheit and Faullant 2018). Configuration theory enables us to investigate the interplay of different DT strategy building blocks and provide a fine-grained view of their interdependencies. Still, it also allows us to highlight insights into individual factors and thereby contribute individually to each DT strategy building block. For example, we confirm the importance of centralized decision-making in the context of DSI (Tronvoll et al. 2020) and highlight the role of DT committees. So far, this concept has received relatively little attention (Chanias et al. 2019) compared to the more common CDO role (see, for example, Haffke et al. (2016); Horlacher et al. (2016); Singh and Hess (2017)).

Lastly, this paper contributes to the methodological variety in the field of IS. While configurational perspectives are slowly gaining popularity, studies with samples of smaller sizes are still an exception (Soto Setzke et al. 2020). Still, we argue that small-N analyses offer several advantages such as familiarity with the cases and more targeted theory building. Adding to the work of Iannacci and Cornford (2018), we show how QCA can be used to calibrate qualitative data, especially semi-structured interviews, to provide insights into novel phenomena, where large samples may be difficult to acquire.

\subsection{Practical Contributions}

For practitioners, our study offers implications for established organizations that want to successfully engage in DSI. First, as a general implication, our configurations can be used as a template by executives. They represent different choices that lead to the same outcome and can, therefore, serve as a basis for decisions regarding the DT strategy, depending on the context of the organization. They can also be used to identify gaps between a failing and a succeeding strategy. For example, if the organization's DT strategy currently resembles configuration B1 and may thus be on a path to failure, they can make the respective changes to reach configuration A1 (i.e., centralizing decision-making and adapting their outsourcing approach).

The second implication relates to decisions regarding the locus of authority. Our configurations reveal that centralization of decision-making is a necessary condition for achieving DSI. Established organizations should, therefore, ensure that their DT strategies are governed by C-level executives. Our case studies show three general options: linking the responsibilities with an existing role such as the CEO or CIO, installing a dedicated role such as a $\mathrm{CDO}$, or implementing a DT committee that consists of multiple executives or managers. Since these decisions appear to work equally well, the organization may select their option considering its individual context. If, for example, the organization currently does not have sufficient resources to promote or hire a dedicated CDO, they can take their first steps by building a DT committee with $\mathrm{C}$-level executives and managers from their established workforce. Gradually, the organization could then start shifting the responsibilities to a dedicated role or may even keep the DT committee if it proves to be successful. 
Third, our results demonstrate the different options for strategic outsourcing. Engaging in strategic outsourcing is part of one recipe for success and our configurations show that its absence can, under certain conditions, lead to failure. A closer analysis of our cases reveals that organizations may avoid outsourcing or engaging in partnerships due to a fear of letting others inside the organization or even due to believing that they can do everything on their own. While this may be a viable approach for large organizations that possess a lot of resources, smaller or mediumsized organizations, in particular, should aim to build a healthy ecosystem of partners that provide the missing capabilities. Ideally, the organization may also learn from this process and build up its own DT capabilities over time.

\section{Limitations and Future Research}

Our approach has limitations that we will now address. Due to the lack of previous research on the influence of DT strategies on DSI, we employed a configurational perspective using fsQCA. We used a relatively small sample of 17 cases, which limits the generalizability of our findings. However, we were mainly interested in providing a first theoretical exploration of the mentioned relationship by using rich, in-depth qualitative data. Future research could further validate our findings by applying regressionbased methods to a larger, representative sample. In this context, the use of qualitative interview data for fsQCA might raise some concerns as well. Although we followed the methodological guidance provided by scholars such as Basurto and Speer (2012) and de Block and Vis (2019) and accounted for interrater reliability, calibrating interview data to fuzzy sets can still raise valid concerns in terms of the interpretability of the results we obtained. However, we carefully explained our coding scheme and provided transparency regarding decisions throughout the calibration process. Additionally, we may have left out dimensions that could be useful in explaining differences in outcome in our research framework. Although consistency and coverage values in our analyses are relatively high, there might be other causal conditions that could allow a different or even more insightful interpretation of the differences that can be observed in the cases.

Furthermore, each of our chosen conditions deserves further investigation. For example, for centralization of decision making, we did not distinguish between the effects of different C-level roles such as CIOs or CDOs (Haffke et al. 2016), nor did we account for different leadership styles such as transformational or transactional leadership. Future research could thus include these strategy elements to test them for effectiveness. Also, here, configuration theory could be applied to identify configurations of strategy elements where, for example, CDOs are more effective than CIOs. Lastly, owing to the exploratory nature of our analysis, we invite fellow researchers to validate our results using, for example, surveys combined with econometric techniques to test the patterns that we proposed in the results section.

\section{Appendix}

Table 5 Case company overview

\begin{tabular}{|c|c|c|c|c|}
\hline Code & Industry & Founded in & Number of employees & Number of interviews \\
\hline Alpha & Entertainment & $2000-$ now & $>100$ & 2 \\
\hline Beta & Consumer goods & 1950-1999 & $>10,000$ & 6 \\
\hline Gamma & Sports & Before 1900 & $>100$ & 3 \\
\hline Delta & Manufacturing & 1900-1949 & $>10,000$ & 6 \\
\hline Epsilon & Industrial manufacturing & 1900-1949 & $>1000$ & 5 \\
\hline Zeta & Industrial manufacturing & 1950-1999 & $>10,000$ & 5 \\
\hline Eta & IT services & 1950-1999 & $>50,000$ & 18 \\
\hline Theta & Industrial manufacturing & Before 1900 & $>10,000$ & 5 \\
\hline Iota & Information security & Before 1900 & $>10,000$ & 10 \\
\hline Kappa & IT services & 1950-1999 & $>10,000$ & 8 \\
\hline Lambda & Sports & 1900-1949 & $>100,000$ & 12 \\
\hline My & Logistics & 2000-now & $>1000$ & 7 \\
\hline $\mathrm{Ny}$ & Industrial manufacturing & Before 1900 & $>50,000$ & 6 \\
\hline $\mathrm{Xi}$ & Entertainment & Before 1900 & $>100$ & 7 \\
\hline Omikron & Industrial manufacturing & 1950-1999 & $>10,000$ & 9 \\
\hline $\mathrm{Pi}$ & Industrial manufacturing & Before 1900 & $>100,000$ & 12 \\
\hline Rho & Consumer goods manufacturing & Before 1900 & $>10,000$ & 9 \\
\hline
\end{tabular}


Table 6 Coding procedure for causal conditions and outcome

\begin{tabular}{|c|c|c|c|c|c|}
\hline $\begin{array}{l}\text { Fuzzy value/ } \\
\text { dimension }\end{array}$ & 0 (fully out) & 0.33 (more out than in) & 0.66 (more in than out) & 1 (fully in) & $\begin{array}{l}\text { Krippendorff's } \\
\text { alpha }\end{array}$ \\
\hline $\begin{array}{l}\text { Structural } \\
\text { separation }\end{array}$ & $\begin{array}{l}\text { No new structures were } \\
\text { created to carry out } \\
\text { digital innovation } \\
\text { activities }\end{array}$ & $\begin{array}{l}\text { Digital innovation activities } \\
\text { take place in newly } \\
\text { created digital business } \\
\text { units }\end{array}$ & $\begin{array}{l}\text { Digital innovation } \\
\text { activities partly take } \\
\text { place in spin-offs while } \\
\text { the main organization } \\
\text { coordinates these activi- } \\
\text { ties }\end{array}$ & $\begin{array}{l}\text { Digital innovation } \\
\text { activities mainly take } \\
\text { place in spin-offs while } \\
\text { the main organization } \\
\text { may partly coordinate } \\
\text { these activities }\end{array}$ & 0.90 \\
\hline $\begin{array}{l}\text { Centralization of } \\
\text { decision-- } \\
\text { making }\end{array}$ & $\begin{array}{l}\text { A team lead or no specific } \\
\text { role is responsible for } \\
\text { governing the DT } \\
\text { strategy }\end{array}$ & $\begin{array}{l}\text { A manager or business unit } \\
\text { leader is responsible for } \\
\text { governing the DT } \\
\text { strategy }\end{array}$ & $\begin{array}{l}\text { A team of C-level execu- } \\
\text { tives and/or managers is } \\
\text { responsible for } \\
\text { governing the DT strat- } \\
\text { egy }\end{array}$ & $\begin{array}{l}\text { A C-level executive (CEO, } \\
\mathrm{CDO}, \mathrm{CIO}, \ldots) \text { is main- } \\
\text { ly responsible for } \\
\text { governing the DT strate- } \\
\text { gy }\end{array}$ & 0.80 \\
\hline $\begin{array}{l}\text { Strategic } \\
\quad \text { outsourcing }\end{array}$ & $\begin{array}{l}\text { Implementing the DT } \\
\text { strategy does not rely on } \\
\text { any external partnerships }\end{array}$ & $\begin{array}{l}\text { External partnerships are } \\
\text { used to implement } \\
\text { certain key aspects of the } \\
\text { DT strategy; the main } \\
\text { implementation effort is } \\
\text { done by the organization }\end{array}$ & $\begin{array}{l}\text { Implementing the DT } \\
\text { strategy relies mostly on } \\
\text { external partnerships, } \\
\text { the organization } \\
\text { implements certain } \\
\text { aspects on its own }\end{array}$ & $\begin{array}{l}\text { Implementing the DT } \\
\text { strategy relies } \\
\text { predominantly on } \\
\text { external partnerships }\end{array}$ & 0.83 \\
\hline $\begin{array}{l}\text { Threat of digital } \\
\text { disruption }\end{array}$ & $\begin{array}{l}\text { The organization's core } \\
\text { business does not face } \\
\text { any considerable threats } \\
\text { of being disrupted in the } \\
\text { foreseeable future by } \\
\text { rival products/services } \\
\text { based on digital technol- } \\
\text { ogies }\end{array}$ & $\begin{array}{l}\text { The organization's core } \\
\text { business might face a } \\
\text { considerable threat of } \\
\text { being disrupted by rival } \\
\text { products/services based } \\
\text { on digital technologies in } \\
\text { the next } 5-10 \text { years }\end{array}$ & $\begin{array}{l}\text { The organization's core } \\
\text { business faces a } \\
\text { considerable threat of } \\
\text { being disrupted by rival } \\
\text { products/services based } \\
\text { on digital technologies } \\
\text { in the next } 3-5 \text { years }\end{array}$ & $\begin{array}{l}\text { The organization's core } \\
\text { business faces an } \\
\text { imminent threat of being } \\
\text { disrupted by rival } \\
\text { products/services based } \\
\text { on digital technologies }\end{array}$ & 0.84 \\
\hline $\begin{array}{l}\text { Digital service } \\
\text { innovation }\end{array}$ & $\begin{array}{l}\text { No new services based on } \\
\text { digital technologies } \\
\text { services were put onto } \\
\text { the market }\end{array}$ & $\begin{array}{l}\text { Services based on digital } \\
\text { technologies were put } \\
\text { onto the market, but they } \\
\text { are mostly based on } \\
\text { incremental innovation } \\
\text { of already existing } \\
\text { services }\end{array}$ & $\begin{array}{l}\text { Services based on digital } \\
\text { technologies were put } \\
\text { onto the market and } \\
\text { they are mostly based } \\
\text { on radical innovation, } \\
\text { partly departing from } \\
\text { the service concepts of } \\
\text { already existing services }\end{array}$ & $\begin{array}{l}\text { Services based on digital } \\
\text { technologies were put } \\
\text { onto the market, they are } \\
\text { based on radical } \\
\text { innovation, entirely } \\
\text { departing from the } \\
\text { service concepts of } \\
\text { already existing services } \\
\text { and they are new to the } \\
\text { organization's industry }\end{array}$ & 0.81 \\
\hline
\end{tabular}


Table 7 Exemplary coding procedure for the construct strategic outsourcing
Fuzzy Illustrative quote(s)
Reason for assignment

value

1 "We found service providers who work for us. We have one for the entire back-end. We have one for the entire front-end"

"Then there is the backend provider [...] But I also have the front-end provider, and all those app providers, and the streaming providers"

"We juggle with 50 freelancers. Both on the programming side as well as on the production side of things. The directing team, they are all freelancers"

All quotes from case $X i$

0.66 "We work a lot with external consultants"

"We care a lot about working with partners. We do not have the know-how for all topics. We know how our business works and we also have the know-how for the applications that we use daily and a bit more. For a lot of topics though, it is very helpful to get know-how from the outside"

"Usually, during such an innovation process we include the digitalization and the IT department. We also do a lot with external consultants"

"We do not have any in-house software developers and the things that we implement are actually always custom software, this means that we need to get help from external developers"

All quotes from case My

0.33 "We did not [engage in acquiring targeted partnerships]. [...] This is also because, due to our organization's diversity in that area, we can do everything on our own. That's why there has not been any partner where we said, okay, now we go with that one regarding this topic. But these are things we need to do in the future [...] This is a part, where we still have difficulties. Until now, we used to be the champion and could always do it on our own, "we can do everything", and engaging strongly in partnerships has not been part of the organization's political agenda."

"We wanted to profit from partners who could provide the software and a part of the digital platform. We arrived at two partnerships: one is actually Anonymized, [...] and there is the content management system, which is Anonymized2, a Swiss provider. And building upon these two and an Anonymized 3 tool we composed what you can now see on the open online shop"

All quotes from case Kappa

0 "Basically, we would like to engage in cooperation and partnerships, but we are coming from a very low baseline"

"I believe that there are many out there who would be interesting for us. Iota is just starting to look for partners and to understand that this is not necessarily something bad"

"I believe Iota is too afraid. Iota does not dare to trust that someone else can bring us benefits and not damage us in some way. I believe it's simply because we are afraid to let someone else into the organization"

All quotes from case Iota
At $\mathrm{Xi}$, virtually all the innovation activities are carried out by service providers and freelancers. Xi partly coordinates these activities ("juggling"), but does not implement any activities on its own

My's DT strategy depends a lot on partnerships and external consultants. However, My also has its own digitalization department that coordinates these activities and they have fundamental know-how about their own applications

Kappa has engaged in partnerships to acquire building blocks for its service innovation. However, these partnerships are limited and due to the organization's mentality of do-it-yourself, the organization has not engaged in further partnerships

As of now, Iota has not engaged in any partnerships to implement its DT strategy 
Table 8 Exemplary coding procedure for case Rho

\begin{tabular}{|c|c|c|c|}
\hline Dimension & $\begin{array}{l}\text { Fuzzy } \\
\text { value }\end{array}$ & Reason for assignment & Illustrative quote/description \\
\hline $\begin{array}{l}\text { Structural } \\
\text { separation }\end{array}$ & 1 & $\begin{array}{l}\text { Innovation activities are mainly conducted in startups that are } \\
\text { independent of the main organization }\end{array}$ & $\begin{array}{l}\text { "What we do at Rho is create, when we have new ideas like } \\
\text { 3D printing etc., we create ventures that stand alone. They } \\
\text { are basically startups and they have the freedom to show } \\
\text { their business value over the next } 2 \text { years" }\end{array}$ \\
\hline $\begin{array}{l}\text { Centralization of } \\
\text { decision-- } \\
\text { making }\end{array}$ & 0.33 & $\begin{array}{l}\text { The DT strategy is mainly led and governed by the head of } \\
\text { digital manufacturing (HDM). While the HDM reports to } \\
\text { the COO, they coordinate all strategy activities }\end{array}$ & $\begin{array}{l}\text { "I'm the head of digital manufacturing and since I am the } \\
\text { program manager responsible for designing, building, and } \\
\text { deployment of the digital backbone as well as the IT part } \\
\text { and the business part and I report to the COO as the head of } \\
\text { manufacturing. So, in Rho the whole digital transformation } \\
\text { is part of operations, so they report to the COO while you } \\
\text { have some companies where the digital program reports to } \\
\text { CIO but in this case, we chose to report to the operations } \\
\text { function for a specific reason" }\end{array}$ \\
\hline $\begin{array}{l}\text { Strategic } \\
\quad \text { outsourcing }\end{array}$ & 0.66 & $\begin{array}{l}\text { Rho is focused on implementing its strategy through } \\
\text { partnerships, while some innovation activities are still } \\
\text { carried out by the main organization }\end{array}$ & $\begin{array}{l}\text { "What we see is that the area is becoming too big to only [be] } \\
\text { handle[d] by Rho so we have quite a lot of strategic } \\
\text { partnerships over there" }\end{array}$ \\
\hline $\begin{array}{l}\text { Threat of digital } \\
\text { disruption }\end{array}$ & 1 & $\begin{array}{l}\text { The core business of Rho is under an imminent threat of } \\
\text { digital disruption }\end{array}$ & $\begin{array}{l}\text { "I think we are running ahead because we have to. Our current } \\
\text { business is stopping in a few years. The biggest worry is, } \\
\text { can we do it fast enough?" }\end{array}$ \\
\hline $\begin{array}{l}\text { Digital service } \\
\text { innovation }\end{array}$ & 0 & $\begin{array}{l}\text { As of today, no services based on digital technologies have } \\
\text { been introduced to the market by Rho }\end{array}$ & \\
\hline
\end{tabular}

Table 9 Fuzzy-set membership score assignment table

\begin{tabular}{llllll}
\hline Case & Structural separation & Centralization of decision-making & Strategic outsourcing & Threat of digital disruption & Digital service innovation \\
\hline Alpha & 0 & 1 & 1 & 0 & 0.33 \\
Beta & 0.33 & 0.66 & 0.66 & 0.33 & 0.66 \\
Gamma & 0.33 & 0.66 & 1 & 0 & 0.33 \\
Delta & 0.33 & 0.66 & 0.66 & 0 & 0.66 \\
Epsilon & 0 & 0.66 & 0.66 & 0.33 & 0.33 \\
Zeta & 1 & 0.33 & 0.66 & 1 & 0 \\
Eta & 0.66 & 1 & 0.33 & 0.33 & 1 \\
Theta & 1 & 0.66 & 1 & 0 & 0.33 \\
Iota & 0.33 & 1 & 0.33 & 0.33 & 0.66 \\
Kappa & 0.33 & 1 & 0 & 0.33 & 0.66 \\
Lambda & 0.66 & 0.66 & 0 & 0.66 & 0.33 \\
My & 0.33 & 1 & 0.66 & 0.33 & 0.33 \\
Ny & 0 & 0.33 & 0.33 & 1 & 0.33 \\
Xi & 0 & 1 & 0.66 & 0 & 1 \\
Omikron & 1 & 0.66 & 0.66 & 0 & 0.66 \\
Pi & 0.66 & 1 & 0.33 & 0.33 & 0.66 \\
Rho & 1 & 1 & 1 & 0.66 & 1 \\
\hline
\end{tabular}


Table 10 Truth table for successful digital service innovation

\begin{tabular}{|c|c|c|c|c|c|c|c|}
\hline $\begin{array}{l}\text { Structural } \\
\text { separation }\end{array}$ & $\begin{array}{l}\text { Centralization of } \\
\text { decision-making }\end{array}$ & $\begin{array}{l}\text { Strategic } \\
\text { outsourcing }\end{array}$ & $\begin{array}{l}\text { Threat of digital } \\
\text { disruption }\end{array}$ & $\begin{array}{l}\text { Successful digital service } \\
\text { innovation }\end{array}$ & $\begin{array}{l}\text { Number of } \\
\text { cases }\end{array}$ & $\begin{array}{l}\text { Raw } \\
\text { consistency }\end{array}$ & $\begin{array}{l}\text { PRI } \\
\text { consistency }\end{array}$ \\
\hline 1 & 1 & 0 & 0 & 1 & 2 & 1.00 & 0.99 \\
\hline 0 & 1 & 0 & 0 & 1 & 2 & 0.99 & 0.96 \\
\hline 1 & 1 & 1 & 0 & 1 & 2 & 0.92 & 0.75 \\
\hline 1 & 1 & 1 & 1 & 1 & 1 & 0.88 & 0.75 \\
\hline 0 & 0 & 0 & 1 & 0 & 1 & 0.79 & 0.00 \\
\hline 1 & 1 & 0 & 1 & 0 & 1 & 0.78 & 0.33 \\
\hline 0 & 1 & 1 & 0 & 0 & 7 & 0.72 & 0.50 \\
\hline 1 & 0 & 1 & 1 & 0 & 1 & 0.33 & 0.00 \\
\hline
\end{tabular}

Table 11 Truth table for unsuccessful digital service innovation

\begin{tabular}{lllllll}
\hline $\begin{array}{l}\text { Structural } \\
\text { separation }\end{array}$ & $\begin{array}{l}\text { Centralization of } \\
\text { decision-making }\end{array}$ & $\begin{array}{l}\text { Strategic } \\
\text { outsourcing }\end{array}$ & $\begin{array}{l}\text { Threat of digital } \\
\text { disruption }\end{array}$ & $\begin{array}{l}\text { Unsuccessful digital service } \\
\text { innovation }\end{array}$ & $\begin{array}{l}\text { Number of } \\
\text { cases }\end{array}$ & $\begin{array}{l}\text { Raw } \\
\text { consistency }\end{array}$ \\
\hline 0 & 0 & 0 & 1 & 1 & 1 & 1.00 \\
consistency
\end{tabular}


Funding Open Access funding enabled and organized by Projekt DEAL.

Open Access This article is licensed under a Creative Commons Attribution 4.0 International License, which permits use, sharing, adaptation, distribution and reproduction in any medium or format, as long as you give appropriate credit to the original author(s) and the source, provide a link to the Creative Commons licence, and indicate if changes were made. The images or other third party material in this article are included in the article's Creative Commons licence, unless indicated otherwise in a credit line to the material. If material is not included in the article's Creative Commons licence and your intended use is not permitted by statutory regulation or exceeds the permitted use, you will need to obtain permission directly from the copyright holder. To view a copy of this licence, visit http://creativecommons.org/licenses/by/4.0/.

\section{References}

Amabile, T. M., Hadley, C. N., \& Kramer, S. J. (2002). Creativity under the gun. Harvard Business Review, 80, 52-63.

Barrett, M., Davidson, E., Prabhu, J., \& Vargo, S. L. (2015). Service innovation in the digital age: Key contributions and future directions. MIS Quarterly, 39(1), 135-154.

Basurto, X., \& Speer, J. (2012). Structuring the calibration of qualitative data as sets for qualitative comparative analysis (QCA). Field Methods, 24(2), 155-174.

Beneito, P., Coscollá-Girona, P., Rochina-Barrachina, M. E., \& Sanchis, A. (2015). Competitive pressure and innovation at the firm level. The Journal of Industrial Economics, 63(3), 422-457.

Berghaus, S., \& Back, A. (2017). Disentangling the fuzzy front end of digital transformation: Activities and approaches. 38th International Conference on Information Systems, Seoul, Korea.

Berg-Schlosser, D., de Meur, G., Rihoux, B., \& Ragin, C. C. (2009). Qualitative comparative analysis (QCA) as an approach. In B. Rihoux \& C. C. Ragin (Eds.), Configurational comparative methods: Qualitative comparative analysis (QCA) and related techniques (pp. 1-18). Thousand Oaks: SAGE Publications, Inc..

Besson, P., \& Rowe, F. (2012). Strategizing information systems-enabled organizational transformation: A transdisciplinary review and new directions. The Journal of Strategic Information Systems, 21(2), 103-124.

Biemans, W. G., Griffin, A., \& Moenaert, R. K. (2016). Perspective: New service development: How the field developed, its current status and recommendations for moving the field forward. Journal of Product Innovation Management, 33(4), 382-397.

de Block, D., \& Vis, B. (2019). Addressing the challenges related to transforming qualitative into quantitative data in qualitative comparative analysis. Journal of Mixed Methods Research, 13(4), 503-535.

Bouncken, R. B., \& Fredrich, V. (2016). Business Model Innovation in Alliances: Successful Configurations. Journal of Business Research, 69(9), 3584-3590.

Brown, A. E., \& Grant, G. G. (2005). Framing the frameworks: A review of IT governance research. Communications of the Association for Information Systems, 15(1), 696-712.

Chanias, S., \& Hess, T. (2016). Understanding digital transformation strategy formation: Insights from Europe's automotive industry. 20th Pacific Asia Conference on Information Systems, Chiayi, Taiwan.

Chanias, S., Myers, M. D., \& Hess, T. (2019). Digital transformation strategy making in pre-digital organizations: The case of a financial services provider. The Journal of Strategic Information Systems, 28(1), 17-33.

Cheng, C. (2011). Dynamic service innovation capability, radical service innovation and open business models. International Journal of Services Technology and Management, 16(3/4), 229.

Corbin, J. M., \& Strauss, A. (1990). Grounded theory research: Procedures, canons, and evaluative criteria. Qualitative Sociology, 13(1), 3-21.
Corley, K. G., \& Gioia, D. A. (2004). Identity ambiguity and change in the wake of a corporate spin-off. Administrative Science Quarterly, 49(2), 173-208.

de Visser, M., de Weerd-Nederhof, P., Faems, D., Song, M., van Looy, B., \& Visscher, K. (2010). Structural ambidexterity in NPD processes: A firm-level assessment of the impact of differentiated structures on innovation performance. Technovation, 30(5-6), 291-299.

Dixon, J., Brohman, K., \& Chan, Y. (2017). Dynamic ambidexterity: Exploiting exploration for business success in the digital age. 38th International Conference on Information Systems, Seoul, Korea.

Dörner, N., Gassmann, O., \& Gebauer, H. (2011). Service innovation: Why is it so difficult to accomplish? Journal of Business Strategy, $32(3), 37-46$.

Dudau, A., Kominis, G., \& Szocs, M. (2017). Innovation failure in the eye of the beholder: Towards a theory of innovation shaped by competing agendas within higher education. Public Management Review, 20(2), 254-272.

Duşa, A. (2019). QCA with R. A comprehensive resource. Cham: Springer International Publishing.

Economides, N., \& Jeziorski, P. (2017). Mobile Money in Tanzania. Marketing Science, 36(6), 815-837.

El Sawy, O. A., Malhotra, A., Park, Y., \& Pavlou, P. A. (2010). Research commentary-Seeking the configurations of digital Ecodynamics: It takes three to tango. Information Systems Research, 21(4), 835-848.

El Sawy, O. A., Kræmmergaard, P., Amsinck, H., \& Vinther, A. L. (2016). How LEGO built the foundations and Enterprise capabilities for digital leadership. MIS Quarterly Executive, 15(2), 141-166.

Fiss, P. C. (2011). Building better causal theories: A fuzzy set approach to typologies in organization research. Academy of Management Journal, 54(2), 393-420.

Frey, A., Trenz, M., \& Veit, D. (2019). A service-dominant logic perspective on the roles of technology in service innovation: Uncovering four archetypes in the sharing economy. Journal of Business Economics, 89(8-9), 1149-1189.

Gilbert, R. J. (2015). E-books: A tale of digital disruption. Journal of Economic Perspectives, 29(3), 165-184.

Goduscheit, R. C., \& Faullant, R. (2018). Paths toward radical service innovation in manufacturing companies-a service-dominant logic perspective. Journal of Product Innovation Management, 35(5), 701-719.

Greckhamer, T., Misangyi, V. F., \& Fiss, P. C. (2013). The two QCAs: From a small-N to a large-N set theoretic approach. In P. C. Fiss, B. Cambré, \& A. Marx (Eds.), Configurational Theory and Methods in Organizational Research (Research in the Sociology of Organizations) (Vol. 38, pp. 49-75). Bingley: Emerald Group Publishing Limited.

Greckhamer, T., Furnari, S., Fiss, P. C., \& Aguilera, R. V. (2018). Studying configurations with qualitative comparative analysis: Best practices in strategy and organization research. Strategic Organization, 16(4), 482-495.

Gresov, C., \& Drazin, R. (1997). Equifinality: Functional equivalence in organization design. Academy of Management Review, 22(2), 403-428.

Guadalupe, M., Li, H., \& Wulf, J. (2014). Who lives in the C-suite? Organizational structure and the division of labor in top management. Management Science, 60(4), 824-844.

Haffke, I., Kalgovas, B. J., \& Benlian, A. (2016). The role of the CIO and the $\mathrm{CDO}$ in an Organization's digital transformation. 37th International Conference on Information Systems, Dublin, Ireland.

Hanelt, A., Bohnsack, R., Marz, D., \& Antunes Marante, C. (2020). A systematic review of the literature on digital transformation: Insights and implications for strategy and organizational change. Journal of Management Studies, forthcoming.

den Hertog, P. (2000). Knowledge-intensive business services as coproducers of innovation. International Journal of Innovation Management, 4(4), 491-528. 
Hess, T., Matt, C., Benlian, A., \& Wiesböck, F. (2016). Options for formulating a digital transformation strategy. MIS Quarterly Executive, 15(2), 123-139.

Hildebrandt, B., Hanelt, A., Firk, S., \& Kolbe, L. (2015). Entering the digital era - the impact of Digital Technology-related M\&as on business model innovations of automobile OEMs. 36th International Conference on Information Systems, Fort Worth, TX, USA.

Horlacher, A. A., Klarner, P. P., \& Hess, T. T. (2016). Crossing boundaries: Organization design parameters surrounding CDOs and their digital transformation activities. 22nd Americas Conference on Information Systems, San Diego, CA, USA.

Hottenrott, H., \& Lopes-Bento, C. (2016). R\&D partnerships and innovation performance: Can there be too much of a good thing? Journal of Product Innovation Management, 33(6), 773-794.

Huang, R., Zmud, R. W., \& Price, R. L. (2010). Influencing the effectiveness of IT governance practices through steering committees and communication policies. European Journal of Information Systems, 19(3), 288-302.

Hund, A., Holotiuk, F., Wagner, H.-T., \& Beimborn, D. (2019). Knowledge management in the digital era: How digital innovation labs facilitate knowledge recombination. 27th European conference on information systems, Stockholm-Uppsala, Sweden.

Iannacci, F., \& Cornford, T. (2018). Unravelling causal and temporal influences underpinning monitoring systems success: A typological approach. Information Systems Journal, 28(2), 384-407.

Ismail, T. (2015). The influence of competitive pressure on innovative creativity. Academy of Strategic Management Journal, 14(2), 117.

Jansen, J. J. P., Van Den Bosch, F. A. J., \& Volberda, H. W. (2006). Exploratory innovation, exploitative innovation, and performance: Effects of organizational antecedents and environmental moderators. Management Science, 52(11), 1661-1674.

Johansson, A. E., Raddats, C., \& Witell, L. (2019). The role of customer knowledge development for incremental and radical service innovation in servitized manufacturers. Journal of Business Research, 98, 328-338.

Ketchen, J. D. J., Combs, J. G., Russell, C. J., Shook, C., Dean, M. A., Runge, J., et al. (1997). Organizational configurations and performance: A meta-analysis. Academy of Management Journal, 40(1), 223-240.

Kleinschmidt, S., Peters, C., \& Leimeister, J. M. (2019). How to scale up contact-intensive services: ICT-enabled service innovation. Journal of Service Management, 31(4), 793-814.

Klinker, K., Wiesche, M., \& Krcmar, H. (2020). Digital transformation in health care: Augmented reality for hands-free service innovation. Information Systems Frontiers, 22, 1419-1431.

Kohtamäki, M., Henneberg, S. C., Martinez, V., Kimita, K., \& Gebauer, H. (2019). A Configurational approach to Servitization: Review and research directions. Service Science, 11(3), 213-240.

Krippendorff, K. (2018). Content analysis: An introduction to its methodology. Thousand Oaks: Sage.

Lee, A. S., \& Baskerville, R. L. (2003). Generalizing generalizability in information systems research. Information Systems Research, 14(3), 221-243.

Leonhardt, D., Hanelt, A., Huang, P., \& Mithas, S. (2018). Does one size fit all? Theorizing governance configurations for digital innovation. 39th International Conference on Information Systems, San Francisco, CA, USA.

Liu, Y., Mezei, J., Kostakos, V., \& Li, H. (2015). Applying configurational analysis to IS behavioural research: A methodological alternative for modelling combinatorial complexities. Information Systems Journal, 27(1), 59-89.

Lusch, R. F., \& Nambisan, S. (2015). Service innovation: A servicedominant logic perspective. MIS Quarterly, 39(1), 155-175.

Markides, C. C. (2013). Business model innovation: What can the ambidexterity literature teach us? Academy of Management Perspectives, 27(4), 313-323.

Matt, C., Hess, T., \& Benlian, A. (2015). Digital transformation strategies. Business \& Information Systems Engineering, 57(5), 339-343.
Mihalache, O. R., Jansen, J. J. P., Van den Bosch, F. A. J., \& Volberda, H. W. (2014). Top management team shared leadership and organizational ambidexterity: A moderated mediation framework. Strategic Entrepreneurship Journal, 8(2), 128-148.

Miles, I. (2005). Innovation in services. In J. Fagerberg, D. C. Mowery, \& R. R. Nelson (Eds.), The Oxford handbook of innovation (pp. 433458). Oxford, UK: Oxford University Press.

Müller, B., \& Renken, U. (2017). Helping Employees to Be Digital Transformers - the Olympus.connect Case. 38th international conference on information systems, Seoul, Korea.

Nishant, R., \& Ravishankar, M. N. (2020). QCA and the harnessing of unstructured qualitative data. Information Systems Journal, 30(5), 845-865.

Paloheimo, H., Lettenmeier, M., \& Waris, H. (2016). Transport reduction by crowdsourced deliveries - A library case in Finland. Journal of Cleaner Production, 132, 240-251.

Pappas, I. O., Kourouthanassis, P. E., Giannakos, M. N., \& Chrissikopoulos, V. (2016). Explaining online shopping behavior with fsQCA: The role of cognitive and affective perceptions. Journal of Business Research, 69(2), 794-803.

Pappas, I. O., Giannakos, M. N., \& Sampson, D. G. (2017). Fuzzy set analysis as a means to understand users of 21 st-century learning systems: The case of mobile learning and reflections on learning analytics research. Computers in Human Behavior, 92, 646-659.

Pappas, I. O., Mikalef, P., Giannakos, M. N., Krogstie, J., \& Lekakos, G. (2018). Big data and business analytics ecosystems: Paving the way towards digital transformation and sustainable societies. Information Systems and e-Business Management, 16(3), 479-491.

Park, Y., El Sawy, O. A., \& Fiss, P. C. (2017). The role of business intelligence and communication Technologies in Organizational Agility: A Configurational approach. Journal of the Association for Information Systems, 18(9), 648-686.

Piccinini, E., Hanelt, A., Gregory, R., \& Kolbe, L. (2015). Transforming industrial business: The impact of digital transformation on automotive organizations. 36th International Conference on Information Systems, Fort Worth, TX, USA.

Ragin, C. C. (2008). Redesigning social inquiry: Fuzzy sets and beyond. Chicago: University of Chicago Press.

Ragin, C. C. (2009). Qualitative comparative analysis using fuzzy sets (fsQCA). In B. Rihoux \& C. Ragin (Eds.), Configurational comparative methods: Qualitative comparative analysis (QCA) and related techniques. Thousand Oaks: Sage Publications.

Reynolds, P., Thorogood, A., \& Yetton, P. W. (2010). Allocation of IT decision rights in multibusiness organizations: What decisions, who makes them, and when are they taken? International Conference on Information Systems, Saint Louis, MO, USA.

Riasanow, T., Soto Setzke, D., Böhm, M., \& Krcmar, H. (2019). Clarifying the notion of digital transformation: A transdisciplinary review of literature. Journal of Competences, Strategy \& Management, 10, 5-36.

Schneider, C. Q., \& Wagemann, C. (2012). Set-theoretic methods for the social sciences: A guide to qualitative comparative analysis. Cambridge, UK: Cambridge University Press.

Sheremata, W. A. (2000). Centrifugal and centripetal forces in radical new product development under time pressure. Academy of Management Review, 25(2), 389-408.

Singh, A., \& Hess, T. (2017). How chief digital officers promote the digital transformation of their companies. MIS Quarterly Executive, 16(1), 1-17.

Singh, A., Klarner, P., \& Hess, T. (2019). How do chief digital officers pursue digital transformation activities? The role of organization design parameters. Long Range Planning, 53(3), 101890.

Sjödin, D., Parida, V., Kohtamäki, M., \& Wincent, J. (2020). An agile cocreation process for digital servitization: A micro-service innovation approach. Journal of Business Research, 112, 478-491. 
Skålén, P., Gummerus, J., von Koskull, C., \& Magnusson, P. R. (2014). Exploring value propositions and service innovation: A servicedominant logic study. Journal of the Academy of Marketing Science, 43(2), 137-158.

Sklyar, A., Kowalkowski, C., Tronvoll, B., \& Sörhammar, D. (2019). Organizing for digital servitization: A service ecosystem perspective. Journal of Business Research, 104, 450-460.

Skog, D. A., Wimelius, H., \& Sandberg, J. (2018). Digital disruption. Business \& Information Systems Engineering, 60(5), 431-437.

Sok, P., \& O'Cass, A. (2015). Achieving service quality through service innovation exploration - Exploitation: The critical role of employee empowerment and slack resources. Journal of Services Marketing, 29(2), 137-149.

Soto Setzke, D., Kavılı, M. C., \& Böhm, M. (2020). On the use of qualitative comparative analysis in information systems research a critical review. 28th European Conference on Information Systems, Marrakesh, Morocco.

Srivastava, S. C., \& Shainesh, G. (2015). Bridging the service divide through digitally enabled service innovations: Evidence from Indian healthcare service providers. MIS Quarterly, 39(1), 245-267.

Teece, D. J. (1996). Firm organization, industrial structure, and technological innovation. Journal of Economic Behavior \& Organization, 31(2), 193-224.

Tóth, Z., Henneberg, S. C., \& Naudé, P. (2017). Addressing the 'qualitative' in fuzzy set qualitative comparative analysis: The generic membership evaluation template. Industrial Marketing Management, 63, 192-204.

Troilo, G., De Luca, L. M., \& Guenzi, P. (2017). Linking data-rich environments with service innovation in incumbent firms: A conceptual framework and research propositions. Journal of Product Innovation Management, 34(5), 617-639.

Tronvoll, B., Sklyar, A., Sörhammar, D., \& Kowalkowski, C. (2020). Transformational shifts through digital servitization. Industrial Marketing Management, 89, 293-305.

Vial, G. (2019). Understanding digital transformation: A review and a research agenda. The Journal of Strategic Information Systems, 28(2), 118-144.

Wagemann, C., Buche, J., \& Siewert, M. B. (2016). QCA and business research: Work in progress or a consolidated agenda? Journal of Business Research, 69(7), 2531-2540.

Weber, A., Haas, M., \& Scuka, D. (2011). Mobile service innovation: A European failure. Telecommunications Policy, 35(5), 469-480.

Wong, E. M., Ormiston, M. E., \& Tetlock, P. E. (2011). The effects of top management team integrative complexity and decentralized decision making on corporate social performance. Academy of Management Journal, 54(6), 1207-1228.

Woodside, A. G. (2014). Embrace•perform•model: Complexity theory, contrarian case analysis, and multiple realities. Journal of Business Research, 67(12), 2495-2503.

Yoo, Y., Henfridsson, O., \& Lyytinen, K. (2010). Research commentaryThe new organizing logic of digital innovation: An agenda for information systems research. Information Systems Research, 21(4), 724-735.

Yoo, Y., Boland, R. J., Lyytinen, K., \& Majchrzak, A. (2012). Organizing for innovation in the digitized world. Organization Science, 23(5), 1398-1408.

Zheng, P., Lin, T.-J., Chen, C.-H., \& Xu, X. (2018). A systematic design approach for service innovation of smart product-service systems. Journal of Cleaner Production, 201, 657-667.

Publisher's Note Springer Nature remains neutral with regard to jurisdictional claims in published maps and institutional affiliations.
David Soto Setzke is a PhD student at the Chair of Information Systems at the Technical University of Munich (TUM), Germany. He holds a Master of Science in Informatics from TUM. His research interests include large-scale digital transformation projects and digital platform ecosystems. His research has been published in journals such as Electronic Markets and the Journal of Competences, Strategy and Management as well as all major IS conference proceedings.

Tobias Riasanow is working on strategy and business development at SAP Labs Munich with the goal of building and growing an innovation ecosystem around SAP. He holds a PhD from TUM about how platform owners can manage the transformation of complementors in their respective ecosystems. He graduated in finance and information management from TUM and Universität Augsburg with a Master of Science with Honors. His practical and academic interests include digital transformation and platform ecosystems. His work has appeared in Business Research, Electronic Markets, the Journal of Competences, Strategy and Management, and leading IS conferences.

Markus Böhm is an interim Professor of Information Systems and Business Process Management at TUM. He graduated in Business \& Information Systems Engineering from Friedrich-Alexander University Erlangen-Nürnberg (FAU) and holds a doctoral degree in Information Systems from TUM. Markus has profound industry experience as a project manager, analyst, and software developer at fortiss, Siemens, Bosch, and BMW among others. His research focus is on mergers $\&$ acquisitions, business model innovation, and digital transformation. Markus has coauthored more than 100 research papers published in all major IS conference proceedings as well as IS, informatics, and business journals including the European Journal of Information Systems (EJIS), Electronic Markets (EM), MIS Quarterly Executive, the Journal of Systems and Software, the Journal of Business Economics, and Business \& Information Systems Engineering.

Helmut Krcmar is a Professor Emeritus of Information Systems with the Department of Informatics, TUM, with a joint appointment with the School of Management, where he is currently the Founding Dean and Delegate Officer of the President - TUM Campus Heilbronn. He has been a Postdoctoral Fellow with IBM Los Angeles Scientific Center, and an Assistant Professor of Information Systems with the Leonard Stern School of Business, NYU, and Baruch College, CUNY. From 1987 to 2002, he was the Chair of Information Systems, Hohenheim University, Stuttgart, where he was the Dean of the Faculty of Business, Economics, and Social Sciences. From 2002 to 2020, he was the Chair of Information Systems with the Department of Informatics, TUM, where he was the Dean from 2010 to 2013. His interdisciplinary work incorporates areas such as accounting, mechanical engineering, and health care. He has co-authored a plethora of research papers published in major IS journals including Management Information Systems Quarterly, Journal of Management Information Systems, Journal of Information Technology, Information Systems Journal, Journal of Strategic Information Systems, European Journal of Information Systems, IEEE Transactions on Engineering Management, Business \& Information Systems Engineering, Communications of the ACM, Information and Management, MIS Quarterly Executive, Information Systems Frontiers, EM, ACM Transactions on Computer-Human Interaction, and Communications of the Association for Information Systems. In Germany, his book Information Management is now in its 6th edition (2015). He collaborates in research with a wide range of leading global organizations. His research interests include information and knowledge management, engineering, piloting, and management of innovative IT-based services, computer support for collaboration in distributed and mobile work and learning processes. Prof. Krcmar is a Fellow of the Association for Information Systems (AIS), (cf. https://aisnet.org/) and a Member of Acatech National Academy of Science and Engineering. 